\title{
Cortical thinning and accumulation of large cortical pores in the tibia reflect local structural deterioration of the femoral neck
}

Citation for published version (APA):

Iori, G., Schneider, J., Reisinger, A., Heyer, F., Peralta, L., Wyers, C., Glueer, C. C., van den Bergh, J. P., Pahr, D., \& Raum, K. (2020). Cortical thinning and accumulation of large cortical pores in the tibia reflect local structural deterioration of the femoral neck. Bone, 137, [115446]. https://doi.org/10.1016/j.bone.2020.115446

Document status and date:

Published: 01/08/2020

DOI:

10.1016/j.bone.2020.115446

Document Version:

Publisher's PDF, also known as Version of record

Document license:

Taverne

Please check the document version of this publication:

- A submitted manuscript is the version of the article upon submission and before peer-review. There can be important differences between the submitted version and the official published version of record.

People interested in the research are advised to contact the author for the final version of the publication, or visit the DOI to the publisher's website.

- The final author version and the galley proof are versions of the publication after peer review.

- The final published version features the final layout of the paper including the volume, issue and page numbers.

Link to publication

\footnotetext{
General rights rights.

- You may freely distribute the URL identifying the publication in the public portal. please follow below link for the End User Agreement:

www.umlib.nl/taverne-license

Take down policy

If you believe that this document breaches copyright please contact us at:

repository@maastrichtuniversity.nl

providing details and we will investigate your claim.
}

Copyright and moral rights for the publications made accessible in the public portal are retained by the authors and/or other copyright owners and it is a condition of accessing publications that users recognise and abide by the legal requirements associated with these

- Users may download and print one copy of any publication from the public portal for the purpose of private study or research.

- You may not further distribute the material or use it for any profit-making activity or commercial gain

If the publication is distributed under the terms of Article $25 \mathrm{fa}$ of the Dutch Copyright Act, indicated by the "Taverne" license above, 
Full Length Article

\title{
Cortical thinning and accumulation of large cortical pores in the tibia reflect local structural deterioration of the femoral neck
}

\author{
Gianluca Iori $^{\mathrm{a}, 1}$, Johannes Schneider ${ }^{\mathrm{a}}$, Andreas Reisinger ${ }^{\mathrm{b}}$, Frans Heyer ${ }^{\mathrm{c}, \mathrm{d}}$, Laura Peralta ${ }^{\mathrm{e}, \mathrm{f}}$, \\ Caroline Wyers ${ }^{\text {, d }}$, Claus C. Glüer ${ }^{g}$, J.P. van den Bergh ${ }^{\text {c,d }}$, Dieter Pahr ${ }^{\mathrm{b}, \mathrm{h}}$, Kay Raum ${ }^{\mathrm{a}, *}$

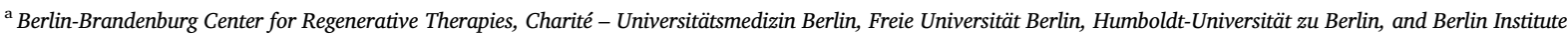 \\ of Health, Berlin, Germany \\ ${ }^{\mathrm{b}}$ Division Biomechanics, Karl Landsteiner University of Health Sciences, Krems, Austria \\ ${ }^{\mathrm{c}}$ Department of Internal Medicine, NUTRIM School of Nutrition and Translational Research in Metabolism, Maastricht University Medical Center, Maastricht, the \\ Netherlands \\ ${ }^{\mathrm{d}}$ Department of Internal Medicine, VieCuri Medical Center, Venlo, the Netherlands \\ ${ }^{\mathrm{e}}$ Laboratoire d'Imagerie Biomédicale, Sorbonne Universités, INSERM UMR S 1146, CNRS UMR 7371, Paris, France \\ ${ }^{\mathrm{f}}$ Department of Biomedical Engineering, School of Biomedical Engineering \& Imaging Sciences, King's College London, London, UK \\ ${ }^{\mathrm{g}}$ Sektion Biomedizinische Bildgebung, Klinik für Radiologie und Neuroradiologie, Christian-Albrechts-Universität zu Kiel, Kiel, Germany \\ ${ }^{\mathrm{h}}$ Institute for Lightweight Design and Structural Biomechanics, TU Wien, Vienna, Austria
}

\section{A R T I C L E I N F O}

\section{Keywords:}

Cortical bone

Porosity

Bone strength

Finite element analysis

Hip fragility

\begin{abstract}
A B S T R A C T
Introduction: Cortical bone thinning and a rarefaction of the trabecular architecture represent possible causes of increased femoral neck (FN) fracture risk. Due to X-ray exposure limits, the bone microstructure is rarely measurable in the FN of subjects but can be assessed at the tibia. Here, we studied whether changes of the tibial cortical microstructure, which were previously reported to be associated with femur strength, are also associated with structural deteriorations of the femoral neck.

Methods: The cortical and trabecular architectures in the FN of 19 humans were analyzed ex vivo on 3D microcomputed tomography images with $30.3 \mu \mathrm{m}$ voxel size. Cortical thickness $\left(\mathrm{Ct} . \mathrm{Th}_{\text {tibia }}\right)$, porosity $\left(\mathrm{Ct} . \mathrm{Po}_{\text {tibia }}\right)$ and pore size distribution in the tibiae of the same subjects were measured using scanning acoustic microscopy (12 $\mu \mathrm{m}$ pixel size). Femur strength during sideways falls was simulated with homogenized voxel finite element models.

Results: Femur strength was associated with the total $\left(\mathrm{vBMD}_{\text {tot }} ; \mathrm{R}^{2}=0.23, p<0.01\right)$ and trabecular $\left(\mathrm{vBMD}_{\text {trab}}\right.$; $\mathrm{R}^{2}=0.26, p<0.01$ ) volumetric bone mineral density (vBMD), with the cortical thickness $\left(\mathrm{Ct} . \mathrm{Th}_{\mathrm{FN}} ; \mathrm{R}^{2}=0.29\right.$, $p<0.001)$ and with the trabecular bone volume fraction $\left(\mathrm{Tb} . \mathrm{BV} / \mathrm{TV}_{\mathrm{FN}} ; \mathrm{R}^{2}=0.34, p<0.001\right.$ ), separation (Tb.Sp $\mathrm{FN}_{\mathrm{FN}} \mathrm{R}^{2}=0.25, p<0.01$ ) and number (Tb. $\mathrm{N}_{\mathrm{FN}} ; \mathrm{R}^{2}=0.32, p<0.001$ ) of the femoral neck. Moreover, smaller Ct.Th $\mathrm{T}_{\text {tibia }}$ was associated with smaller Ct.Th $\mathrm{FN}_{\left(\mathrm{R}^{2}=0.31, p<0.05\right) \text {, lower Tb.BV/TV }}\left(\mathrm{R}^{2}=0.29\right.$, $p<0.05)$, higher Tb.Sp $\mathrm{p}_{\mathrm{FN}}\left(\mathrm{R}^{2}=0.33, p<0.05\right)$ and lower Tb. $\mathrm{N}_{\mathrm{FN}}\left(\mathrm{R}^{2}=0.42, p<0.01\right)$. A higher prevalence of pores with diameter $>100 \mu \mathrm{m}$ in tibial cortical bone (relCt.Po $\mathrm{O}_{100 \mu \mathrm{m}-\text { tibia }}$ ) indicated higher Tb.Sp $\mathrm{FN}_{\mathrm{FN}}$ $\left(\mathrm{R}^{2}=0.36, p<0.01\right)$ and lower Tb. $\mathrm{N}_{\mathrm{FN}}\left(\mathrm{R}^{2}=0.45, p<0.01\right)$.

Conclusion: Bone resorption and structural decline of the femoral neck may be identified in vivo by measuring cortical bone thickness and large pores in the tibia.
\end{abstract}

\section{Introduction}

The hierarchical structure of bone fulfills the mechanical function (i.e., a combined need for rigidity and strength while preserving minimum weight) dictated by efficient locomotion in a gravity environment [1]. In the human femoral neck (FN), the bone architecture is adapted to withstand the stress field generated by physiological motor tasks [2,3]. Despite the heterogeneous strain distribution encountered while performing everyday movements [4], this can be generalized as a compression throughout the inferior aspect of the neck

\footnotetext{
* Corresponding author at: Berlin-Brandenburg Center for Regenerative Therapies (BCRT), Charité - Universitätsmedizin Berlin, Augustenburger Platz 1, 13353 Berlin, Germany.

E-mail address: kay.raum@charite.de (K. Raum).

${ }^{1}$ The present address of GI is: Synchrotron-light for Experimental Science and Applications in the Middle East (SESAME). Allan 19252, Jordan
} 
along with tension in the superior arcade [5]. By causing an inversion of the habitual strains in the neck [6,7], sideways falls are associated with the greatest fracture risk for the hip [8]. During this event, FN fractures initiate in the superior aspect of the neck, where bone experiences a peak in compressive strain $[7,9]$.

The cortical bone in the superior, sub-capital region of the neck is thinner in individuals who sustained an osteoporotic hip fracture with respect to healthy controls, likely constituting a reason of neck fragility [10-12]. Structural instability arising from a thin superior cortex might be accompanied by a sparse and rarefied trabecular network [13] providing insufficient structural redundancy [14]. Cumulative deteriorations of both cortical and trabecular compartments have been associated with reduced FN strength [15]. Despite evidence supporting the particular role of the local femoral neck microarchitecture in determining femur strength, current technology does not allow its assessment in subjects in a non-invasive manner.

Microstructural measurements performed with High-Resolution peripheral Quantitative Computed Tomography (HR-pQCT) at the tibia can capture age related bone loss and remodeling [16,17] and might represent an important surrogate of femur strength for the prediction of the individual's fracture risk [18]. Ultrasound (US) waves interacting with the cortical bone of the tibia also contain structural information that can be employed in several ways. The combined estimation of cortical thickness and porosity has been achieved by means of full-wave dispersion analysis of guided waves in axial transmission measurements [19]. Several refraction-corrected imaging approaches have been proposed, which provide i) real-time image guidance during the measurement and ii) local estimates of cortical thickness and sound velocity $[20,21]$. The latter is commonly used as a surrogate measure of cortical porosity [21,22]. Moreover, in-silico [23] and first experimental studies [24] suggested that information about cortical porosity, pore size, and pore density can be obtained from waves backscattered from cortical pores. The most suitable cortical bone measurement site is the anteriormedial part of the tibia midshaft, as it is easily accessible (using secondgeneration HR-pQCT and quantitative bone ultrasound), load-bearing, has a relatively high thickness and a low amount of soft tissue on the sound propagation path.

In a previous ex vivo investigation on human cadaver bones, we have reported significant associations between properties of the cortical bone microstructure in the anteromedial tibia and femur strength [25]. Particularly, we observed strong correlations of femur strength with tibial cortical thickness $(r=0.81)$ and cross-sectional geometry ( $r=0.48$ to 0.73 ) of the same leg. Most importantly, cortical porosity (Ct.Po) of the tibia was not associated with any of the femoral parameters, but the prevalence of large pores (pores with a diameter larger than $100 \mu \mathrm{m}$ ) was associated with hip strength in both standing $(\mathrm{r}=-0.63)$ and falling $(\mathrm{r}=-0.48)$ conditions [25].

In this work, we link microstructural changes of tibial cortical bone with microstructural changes in the femoral neck and determine their impacts on the reduction of femur strength. For this, we analyze the local microarchitecture of cortical and trabecular bone in previously measured HR-pQCT data [25] from the left and right femoral necks of 19 human donors together with the cortical microarchitecture on acoustic microscopy images of the left tibiae from the same subjects. To the best of the authors' knowledge, the association between the bone microstructure in the tibia and in the femoral neck has not been investigated so far.

\section{Materials and methods}

\subsection{Samples}

The left and right femora and the left tibiae of nineteen human donors (6 male, 13 female, age: 69-94 years, mean: $84 \pm 8$ years) were obtained in accordance with the German law "Gesetz über das Leichen-, Bestattungs- und Friedhofswesen des Landes Schleswig-
Holstein - Abschnitt II, §9 (Leichenöffnung, anatomisch)" from 04.02.2005.

\subsection{High resolution peripheral quantitative computed tomography}

HR-pQCT images of proximal femur samples were obtained in a previous study [26]. Briefly, the bones were submerged in $1 \%$ PBS, degassed and scanned inside a custom sealed chamber using a secondgeneration HR-pQCT scanner (XtremeCT II, Scanco Medical AG, Brüttisellen, Switzerland) setting X-ray tube voltage at $68 \mathrm{kVp}$, current at $1470 \mu \mathrm{A}$ and applying $200 \mathrm{~ms}$ integration time. The projections (3000, taken over $180^{\circ}$ ) were reconstructed as stacks of $4608 \times 4608$ images with isotropic voxel size of $30.3 \mu \mathrm{m}$. Voxel Hounsfield Units (HU) were converted to volumetric bone mineral density (vBMD) using the scanner built-in calibration rule.

\subsection{Simulations of proximal femur strength}

The failure of the proximal femora under quasi-static sideways fall load conditions was simulated using non-linear homogenized voxel finite element (hvFE) models that were derived from the HR-pQCT images following a validated protocol [27]. Details of the development and validation of these models were described in previous works [25,28]. The HR-pQCT datasets were coarsened to $2.7 \mathrm{~mm}$ isotropic voxels and converted to bone volume fraction. Elastic and yield properties depended on local damage [29] and were initially mapped on the model using an empirical function of the bone volume fraction of single voxels $[27,30]$. The FE models were generated with medtool 4.1 (Dr. Pahr Ingenieurs e.U, Pfaffstätten, Austria) and solved in Abaqus 6.12 (Simulia, Dassault Systemes, Velizy, France). The maximum force recorded during the simulation was taken as the femoral strength.

\subsection{Scanning acoustic microscopy}

Scanning Acoustic Microscopy (SAM) images of a cross-section from the midshaft region of each tibia (Fig. 1B) were obtained within a previous study [25]. In short, sections were washed and prepared by removing soft tissues and by grinding and polishing one surface on a planar grinder (Phoenix 4000, Buehler Ltd., Illinois). Scanning was performed with a custom-built acoustic microscope [31,32], maintaining the sample at a fixed temperature of $25{ }^{\circ} \mathrm{C}$ in $1 \%$ degassed PBS solution. The microscope was equipped with a KSI transducer (KSI 100/ $60^{\circ}$, KSI, Herborn, Germany) with a central frequency of $100 \mathrm{MHz}$, and a lateral resolution (diameter of the focused ultrasound beam in the focal plane) of $19.8 \mu \mathrm{m}$ [32]. Radio frequency signals were processed and converted to acoustic impedance maps with a pixel size of $12 \mu \mathrm{m}$ (Fig. 1A) as described in previous works [32,33]. SAM images can be downloaded from: doi:https://doi.org/10.5281/zenodo.2593855.

\subsection{Image processing}

\subsubsection{Femoral neck}

A 7-mm thick cross section of each FN was extracted for microstructural characterization from the HR-pQCT datasets perpendicular to the neck anatomical axis [34] (Fig. 2B). Since the neck strength strongly depends on location along its axis [35], the sections were centered around the cross-section with minimum area [36]. The volume was filtered with a Gaussian kernel (sigma $=1.06$ voxels) to remove high frequency noise, coarsened with factor 2 (yielding $60.6 \mu \mathrm{m}$ voxel size) and rotated to align the image $Z$-axis with the neck anatomical axis and the inferior aspect of the neck towards the bottom of the image (Fig. 2A). A binary mask of the cortical bone (green in Fig. 2A and C) was obtained applying the automatic procedure proposed for tibia images by Burghardt et al. [37], followed by a manual correction step which was required by the much thinner cortical bone in the neck. Trabecularized regions of the neck, where it was not possible to identify 


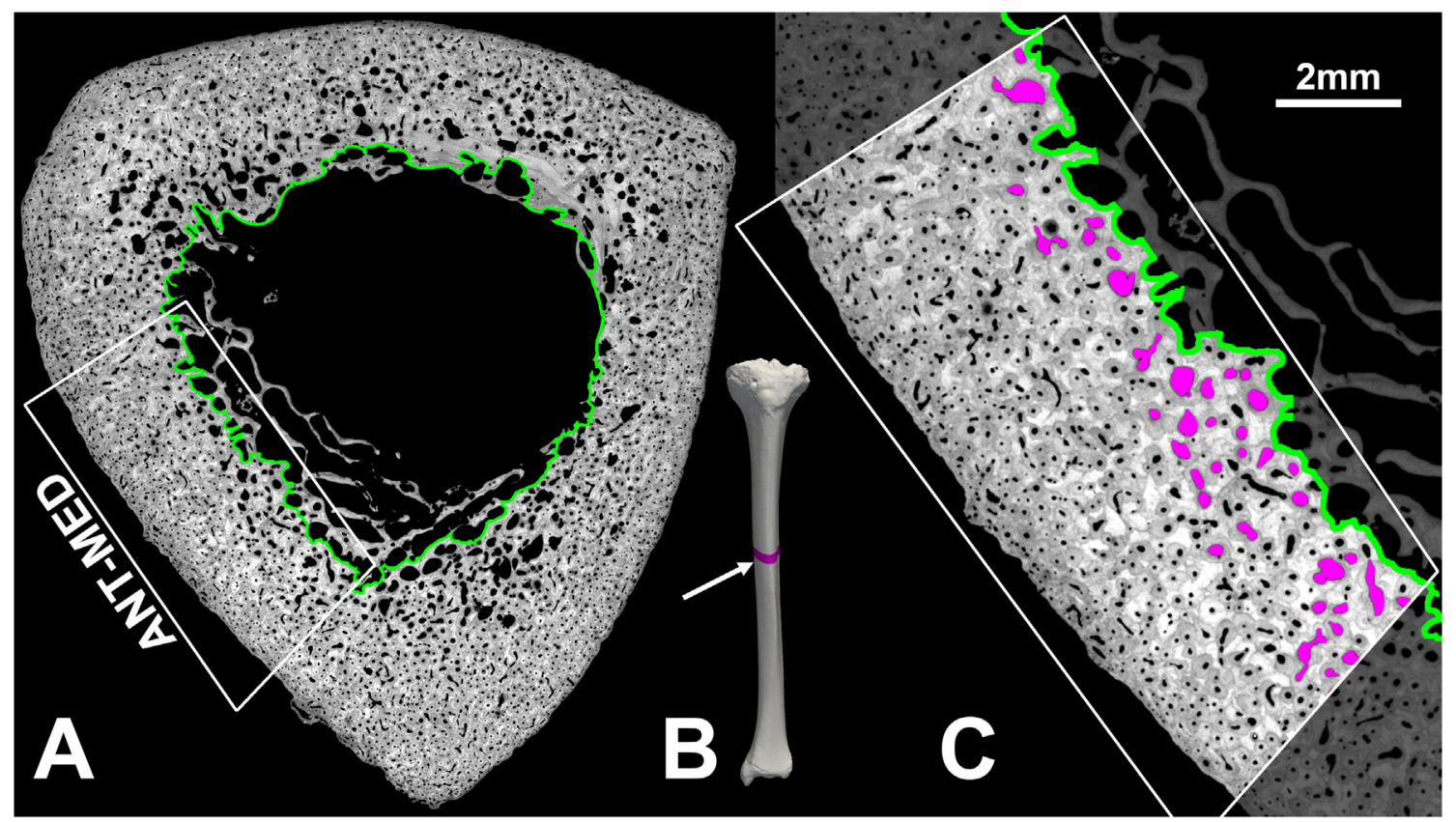

Fig. 1. 2D histomorphometric analysis of the tibia midshaft by SAM. A cross section of the tibia midshaft is scanned with SAM (A). Cortical and trabecular bone compartments are separated (green) and cortical thickness, porosity and pore size measurements are performed on the anterior-medial portion of cortical bone below the facies medialis of the tibia (white box in A and arrow in B). Pores with a diameter larger than $100 \mu \mathrm{m}$ are highlighted in magenta in (C), where a detail of the anteromedial region of (A) is shown. (For interpretation of the references to colour in this figure legend, the reader is referred to the web version of this article.)

compact cortical bone tissue were manually marked on each slice of the stack (Fig. 2C) using Amira (Zuse Institute Berlin, Germany). The neck was then divided in twelve $30^{\circ}$-wide circumferential sectors (Fig. 2A) to analyze local bone structure and vBMD. Binary masks of trabecular and cortical tissue were segmented independently by computing thresholds from the intensity histogram of the two bone regions separately [38]. Local trabecular number (Tb. $\mathrm{N}_{\mathrm{FN}}$ ), thickness $\left(\mathrm{Tb} . \mathrm{Th}_{\mathrm{FN}}\right)$ and separation (Tb.Sp $\mathrm{P}_{\mathrm{FN}}$ ) were measured in medtool 4.1 (Dr. Pahr Ingenieurs e.U, Pfaffstätten, Austria). Cortical bone thickness $\left(\mathrm{Ct} . \mathrm{Th}_{\mathrm{FN}}\right)$ was measured as the mean of the distance distribution between periosteum and endosteum contours [39], after removing areas of complete trabecularization. Trabecular bone volume fraction (Tb.BV/TV) was measured from the binary images of the bone tissue and of the trabecular bone compartment. To obtain a value for each one of the quadrants (inferior, anterior, superior and posterior), measurements from 3 adjacent sectors $\left(90^{\circ}\right.$ in total) were smoothed with a Gaussian kernel $(\sigma=1.2)$. Measurements were also performed on the whole FN. Apart from the exceptions reported in the text, image processing was conducted in Matlab (R2018a, The Mathworks Inc., Natick, MA, USA).

\subsubsection{Tibia}

SAM images of the tibia (Fig. 1) were binarized applying a global

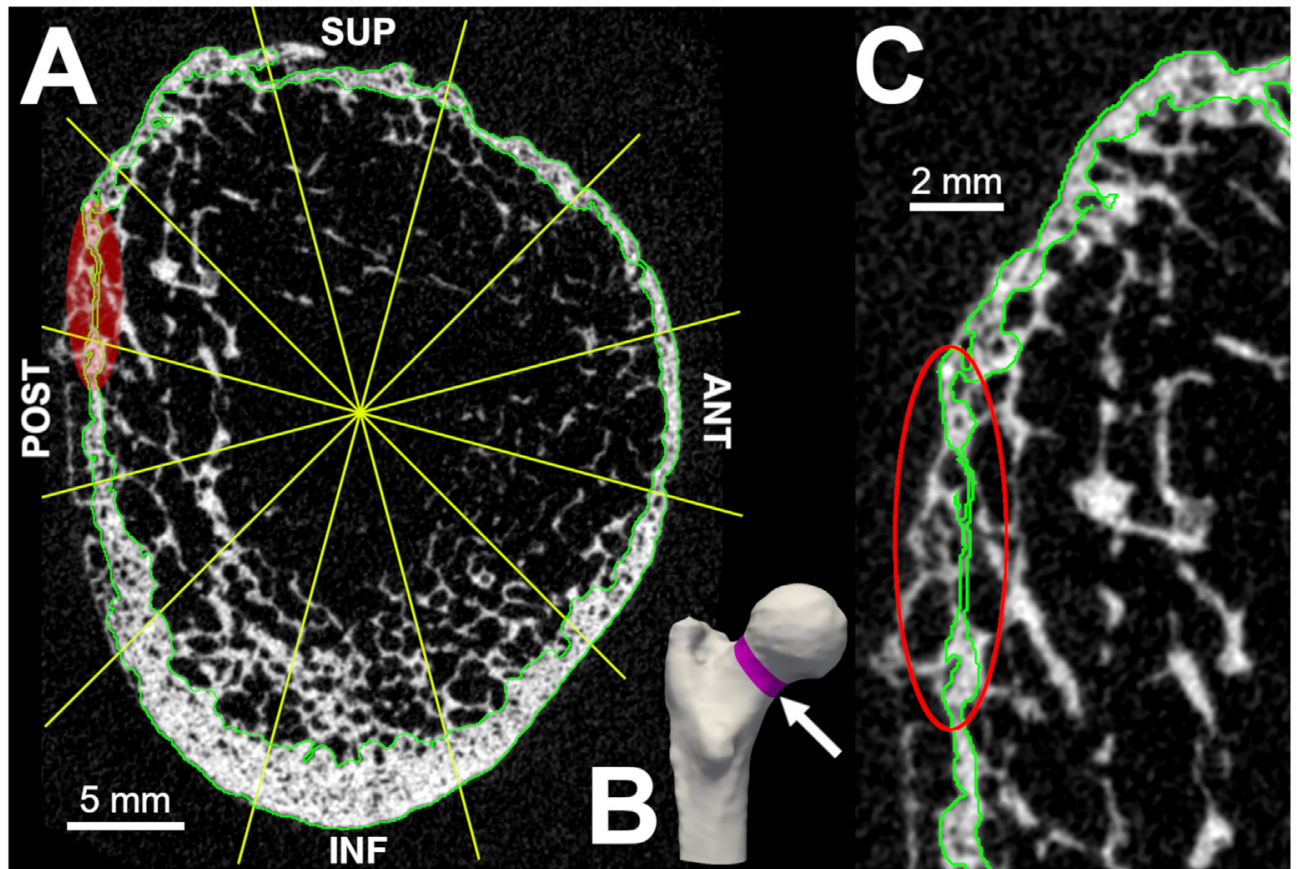

Fig. 2. 3D histomorphometric analysis of the femoral neck. (A) $7 \mathrm{~mm}$ of the neck (magenta in B) were extracted perpendicular to the neck axis for histomorphometric and density measurements. The section was rotated in a standard anatomical reference plane (inferior-medial region pointing towards the bottom of the image) and divided into 12 circumferential sectors with $30^{\circ}$ width. (C) Detail of a trabecularized region (superior-posterior) of the cortex. (For interpretation of the references to colour in this figure legend, the reader is referred to the web version of this article.) 
adaptive threshold [40]. Structures with area $>0.144 \mathrm{~mm}^{2}$ and not connected to the main bone tissue were removed and all single-pixel voids were filled. The cortical bone was manually separated from the trabecularized regions according to a set of rules described for SAM images with the same resolution [41]. Ct.Th $\mathrm{Ttibia}_{\text {, }} \mathrm{Ct}^{\mathrm{P} \mathrm{Po}_{\text {tibia }}}$ and single pore diameters (Po.Dm $\left.\mathrm{tibia}_{\text {ia }}\right)$ were computed on the anteromedial portion of the shaft (Fig. 1C; arrow in Fig. 1B) since this region represents the target of in vivo measurements of cortical bone with quantitative ultrasound. The contribution to the total $\mathrm{Ct} \mathrm{Po}_{\text {tibia }}$ of only pores with diameter larger than $100 \mu \mathrm{m}$ (magenta in Fig. 1C) was also quantified

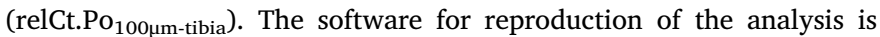
available at: https://doi.org/10.5281/zenodo.2605365.

\subsection{Statistical analysis}

Parameters were tested for normality using the Shapiro-Wilk test. For each microstructural or vBMD measurement in the FN, the difference between inferior, anterior, superior and posterior quadrants was tested by one-way ANOVA or Kruskal-Wallis test, depending on the normality of the parameter distribution. If the test indicated significant differences, pairs of quadrants were compared with a paired Student's $t$ test or with a Wilcoxon signed-rank test, for normally or non-normally distributed parameters, respectively. The $\mathrm{R}^{2}$ of the linear regression was used to assess the degree of association between i) femur strength and FN microstructure or vBMD, and ii) cortical microstructure of the tibia and microstructure or vBMD of the FN. To control for the effect of body size, linear regressions with femur strength were repeated after correcting strength values for the total length of the femur or for the average cross-sectional area of the femoral neck. When comparing single quadrants within the $\mathrm{FN}$, a Bonferroni correction was applied with $\mathrm{m}=4$ and overall significance level $\alpha=0.05$. The significance level of single linear regressions was therefore set at $p=0.05$ / $4=0.0125$. The comparison between tibial and FN microstructures was repeated considering only left, only right or the average between left and right FN properties. All analyses were repeated excluding circumferential sectors of the FN in which trabecularized areas exceeded $50 \%$ of the external neck surface. This was done to verify that trabecularized regions did not affect the calculation of femoral neck cortical bone parameters.

\section{Results}

\subsection{Associations between femoral neck microstructure or $v B M D$ and femur} strength

The strength of the proximal femur was associated with the total and trabecular femoral neck vBMD $\left(\mathrm{R}^{2}=0.23\right.$ and $\mathrm{R}^{2}=0.26$ respectively, both $p<0.01$; Table 1$)$, with $\mathrm{Ct}_{\mathrm{Th}} \mathrm{Th}_{\mathrm{FN}}\left(\mathrm{R}^{2}=0.29\right.$, $p<0.001$; Table 1) as well as with Tb.BV/TV $\mathrm{FN}, \mathrm{Tb}_{\mathrm{SP}} \mathrm{PN}_{\mathrm{FN}}$ and $\mathrm{Tb} . \mathrm{N}_{\mathrm{FN}}$ $\left(\mathrm{R}^{2}=0.34, \mathrm{R}^{2}=0.25\right.$ and $\mathrm{R}^{2}=0.32$ respectively, all $p<0.001$; Table 1). The same parameters of the femoral neck remained associated with femur strength even after correcting the latter for total femur length or for femoral neck cross-sectional area (Supplemental Table 3).

\subsubsection{Analyses of single femoral neck quadrants}

The distributions of vBMD and microstructural properties in the FN (Fig. 3) showed a clear regional pattern. The inferior FN had a thicker (Fig. 3D) and denser (Fig. 3B) cortical bone, as well as higher Tb.BV/TV (Fig. 3E) and Tb.Th (Fig. 3F). Heavy or complete trabecularization of the outer femoral neck perimeter was mostly observed in the posterior aspect of the FN.

The associations between femur strength and $\mathrm{vBMD}_{\text {tot }}\left(\mathrm{R}^{2}=0.33\right.$, $p<0.001$; Fig. 4A), and Ct.Th $\mathrm{Th}_{\mathrm{FN}}\left(\mathrm{R}^{2}=0.43, p<0.001\right.$; Fig. 4D) were particularly strong when these properties were assessed in the superior quadrant of the $\mathrm{FN}\left(+10 \%\right.$ and $+14 \%$ with respect to the $\mathrm{R}^{2}$ of whole FN properties, respectively). There was no association between femur strength and the local $\mathrm{vBMD}_{\text {cort }}$ (Fig. 4B) of the femoral neck. After excluding trabecularized regions of the cortical bone, femur strength remained strongly associated with $\mathrm{Ct} . \mathrm{Th}_{\mathrm{FN}}$ in the superior neck quadrant $\left(\mathrm{R}^{2}=0.30, p<0.001\right.$; Supplemental Fig. 1). Properties of the trabecular architecture showed similar or stronger associations with femur strength when assessed over the entire FN (Fig. 4E to G).

\subsection{Tibial cortical bone microstructure reflects bone architecture in the femoral neck}

The coefficients of determination reported in this paragraph refer to the linear regression between left tibia properties and average quantities from the left and right femoral necks. Significant associations were confirmed by comparing the left tibia separately with the left or with the right vBMD and microstructure of the FN (Supplemental Table 1).

Ct. $\mathrm{Th}_{\text {tibia }}$ was associated with $\mathrm{Ct} . \mathrm{Th}_{\mathrm{FN}}\left(\mathrm{R}^{2}=0.31, p<0.05\right.$; Table 1 and Fig. 5A), Tb.BV/TV $\mathrm{FN},\left(\mathrm{R}^{2}=0.29, p<0.05\right.$; Table 1 and Fig. $5 \mathrm{~B}), \mathrm{Tb} . \mathrm{Sp}_{\mathrm{FN}}\left(\mathrm{R}^{2}=0.33, p=0.01\right.$; Table 1 and Fig. $\left.5 \mathrm{C}\right)$ and $\mathrm{Tb} . \mathrm{N}_{\mathrm{FN}}$ $\left(\mathrm{R}^{2}=0.42\right.$, all $p<0.01$; Table 1 and Fig. 5D) of the whole FN. Ct.Th $\mathrm{T}_{\text {tibia }}$ was strongly associated with $\mathrm{Ct}$. Th $\mathrm{FN}_{\mathrm{FN}}$ in the superior-anterior aspect of the $\mathrm{FN}\left(\mathrm{R}^{2}>0.33, p<0.01\right.$; Fig. $\left.5 \mathrm{~A}\right)$ and with $\mathrm{Tb} . \mathrm{BV} / \mathrm{TV}_{\mathrm{FN}}$ $\left(\mathrm{R}^{2}=0.32, p<0.01\right.$; Fig. 5B), Tb.Sp $\mathrm{p}_{\mathrm{FN}}\left(\mathrm{R}^{2}=0.39, p<0.01\right.$; Fig. $5 \mathrm{C})$ and Tb. $\mathrm{N}_{\mathrm{FN}}\left(\mathrm{R}^{2}=0.59\right.$, all $p<0.001$; Fig. $\left.5 \mathrm{D}\right)$ in the inferior FN. The association between Ct.Th $\mathrm{Th}_{\text {tibia }}$ and Ct.Th $\mathrm{FN}_{\mathrm{F}}$ was limited to the anterior FN after excluding trabecularized regions of the cortex (panel B

Table 1

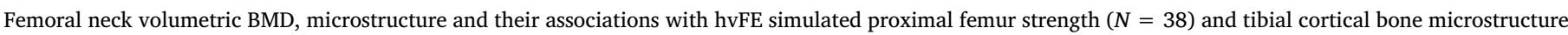
$(N=19)$.

\begin{tabular}{|c|c|c|c|c|c|c|c|}
\hline & \multirow[b]{3}{*}{ Mean \pm SD (min-max) } & \multirow[b]{3}{*}{ CV [\%] } & \multirow{3}{*}{$\begin{array}{l}\text { Femur } \\
\text { Strength } \\
\mathrm{R}^{2}\end{array}$} & \multicolumn{4}{|l|}{ Tibia } \\
\hline & & & & Ct.Th & Ct.Po & Po.Dm & relCt.Po $\mathrm{Po}_{100 \mu \mathrm{m}}$ \\
\hline & & & & & & & \\
\hline$v B M D_{\text {tot }}\left[\mathrm{mgHA} / \mathrm{cm}^{3}\right]$ & $214 \pm 49(126-314)$ & 23 & $0.23^{*}$ & & & & \\
\hline$v B M D_{\text {cort }}\left[\mathrm{mgHA} / \mathrm{cm}^{3}\right]$ & $801 \pm 44(688-885)$ & 6 & & & $0.58^{* *}$ & $0.48^{* *}$ & 0.31 \\
\hline$v B M D_{\text {trab }}\left[\mathrm{mgHA} / \mathrm{cm}^{3}\right]$ & $85 \pm 38(23-189)$ & 45 & $0.26^{* *}$ & & & & \\
\hline Ct.Th $[\mathrm{mm}]$ & $0.95 \pm 0.19(0.60-1.37)$ & 20 & $0.29^{* *}$ & 0.31 & & & \\
\hline$T b . B V / T V[\%]$ & $15.8 \pm 3.7(10.7-24.2)$ & 24 & $0.34^{* *}$ & 0.29 & & & \\
\hline$T b . T h[\mathrm{~mm}]$ & $0.28 \pm 0.02(0.24-0.34)$ & 9 & & & & & \\
\hline $\operatorname{Tb} . S p[\mathrm{~mm}]$ & $1.46 \pm 0.58(0.92-3.37)$ & 40 & $0.25^{* *}$ & $0.33^{*}$ & & & $0.36^{*}$ \\
\hline $\operatorname{Tb} . N[\mathrm{~mm}]$ & $0.65 \pm 0.13(0.39-0.87)$ & 20 & $0.32^{* *}$ & 0.42 & & & $0.45^{*}$ \\
\hline
\end{tabular}

$\mathrm{SD}=$ standard deviation; $\mathrm{CV}=$ coefficient of variation; hvFE $=$ homogenized voxel finite element. Coefficients are reported only for $p$-values $<0.05$.

$* p \leq 0.01$.

*** $p \leq 0.001$. 

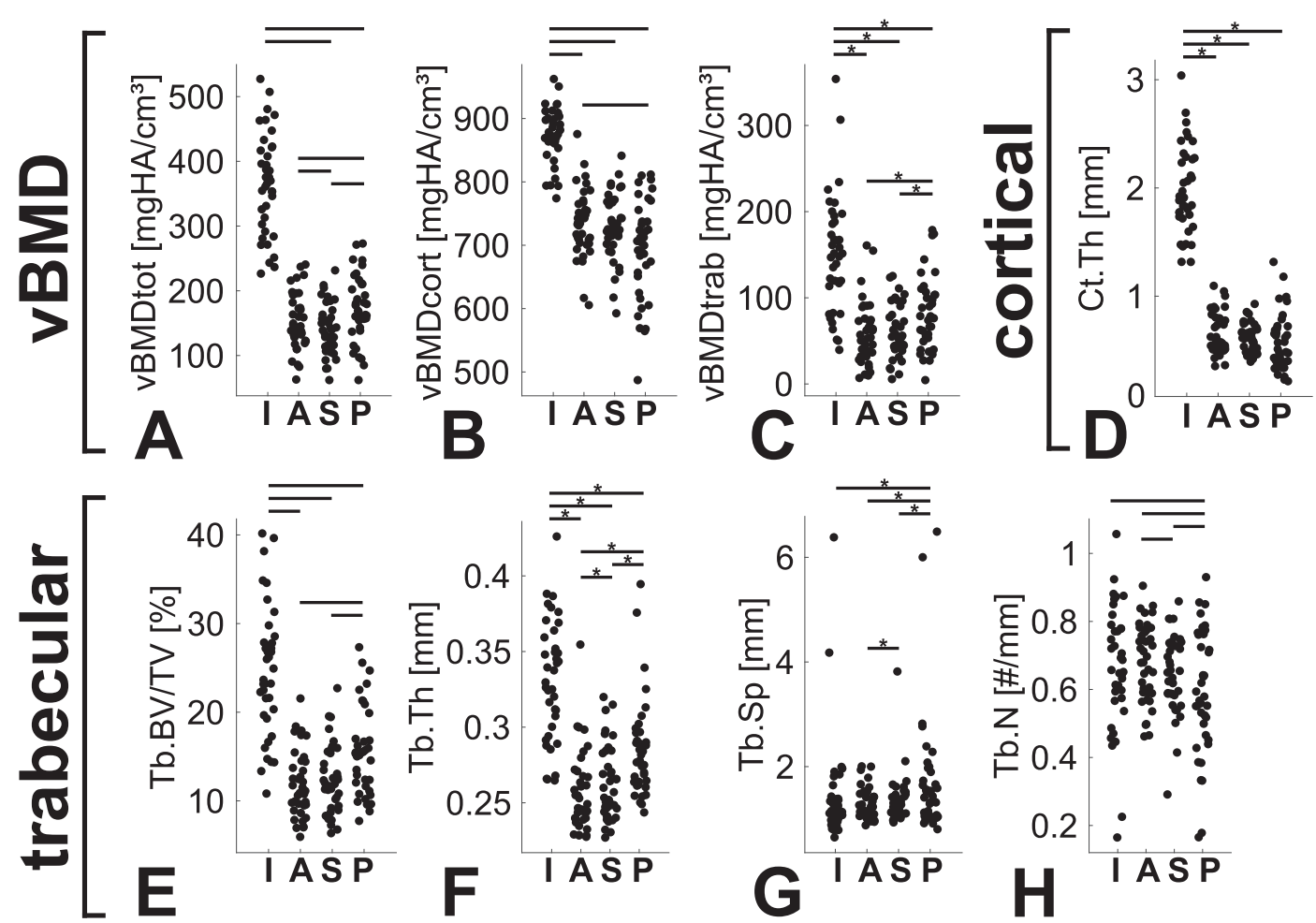

Fig. 3. Local vBMD and microstructure in the quadrants of the femoral neck. Higher vBMD $\mathrm{D}_{\text {tot }}(\mathrm{A}), \mathrm{vBMD}_{\text {cort }}(\mathrm{B})$ and $\mathrm{vBMD}$ trab $(\mathrm{C}), \operatorname{larger} \mathrm{Ct}$.Th $\mathrm{FN}_{\mathrm{FN}}(\mathrm{D}), \mathrm{Tb}_{\mathrm{BVV}} / \mathrm{TV}_{\mathrm{FN}}(\mathrm{E})$ and $\mathrm{Tb}_{\mathrm{Th}} \mathrm{TN}(\mathrm{F})$ were found in the inferior femoral neck. Posteriorly, trabeculae had larger separation (G) and lower number (H). The letters I, A, S and P on the horizontal axes indicate inferior, anterior, superior and posterior quadrants, respectively. * indicates a Wilcoxon signed-rank test. Left and right measurements are pooled. $(N=38)$.

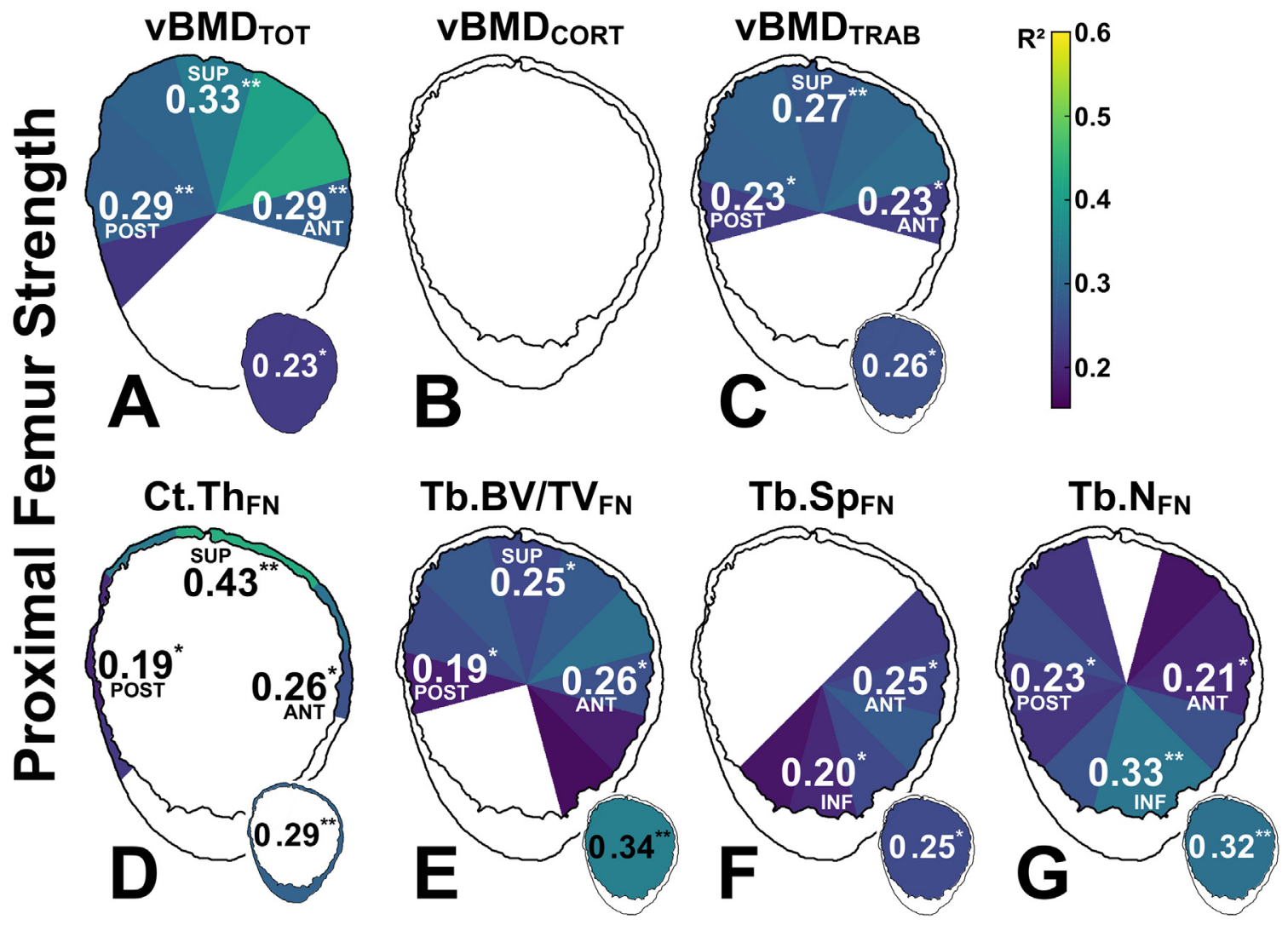

Fig. 4. Structural determinants of femur strength. The ultimate force registered during a simulated sideways fall was associated with vBMD $D_{\text {tot }}(A)$, $v B M D_{\text {trab }}(C)$, Ct. $\mathrm{Th}_{\mathrm{FN}}(\mathrm{D}), \mathrm{Tb} . \mathrm{BV} / \mathrm{TV}_{\mathrm{FN}}(\mathrm{E}), \mathrm{Tb} . \mathrm{Sp}_{\mathrm{FN}}(\mathrm{F})$ and Tb. $\mathrm{N}_{\mathrm{FN}}(\mathrm{G})$ of the femoral neck. Colored areas have $p<0.05 . * p<0.01 .{ }^{* *} p<0.001 . N=38$. (For interpretation of the references to color in this figure legend, the reader is referred to the web version of this article.) 

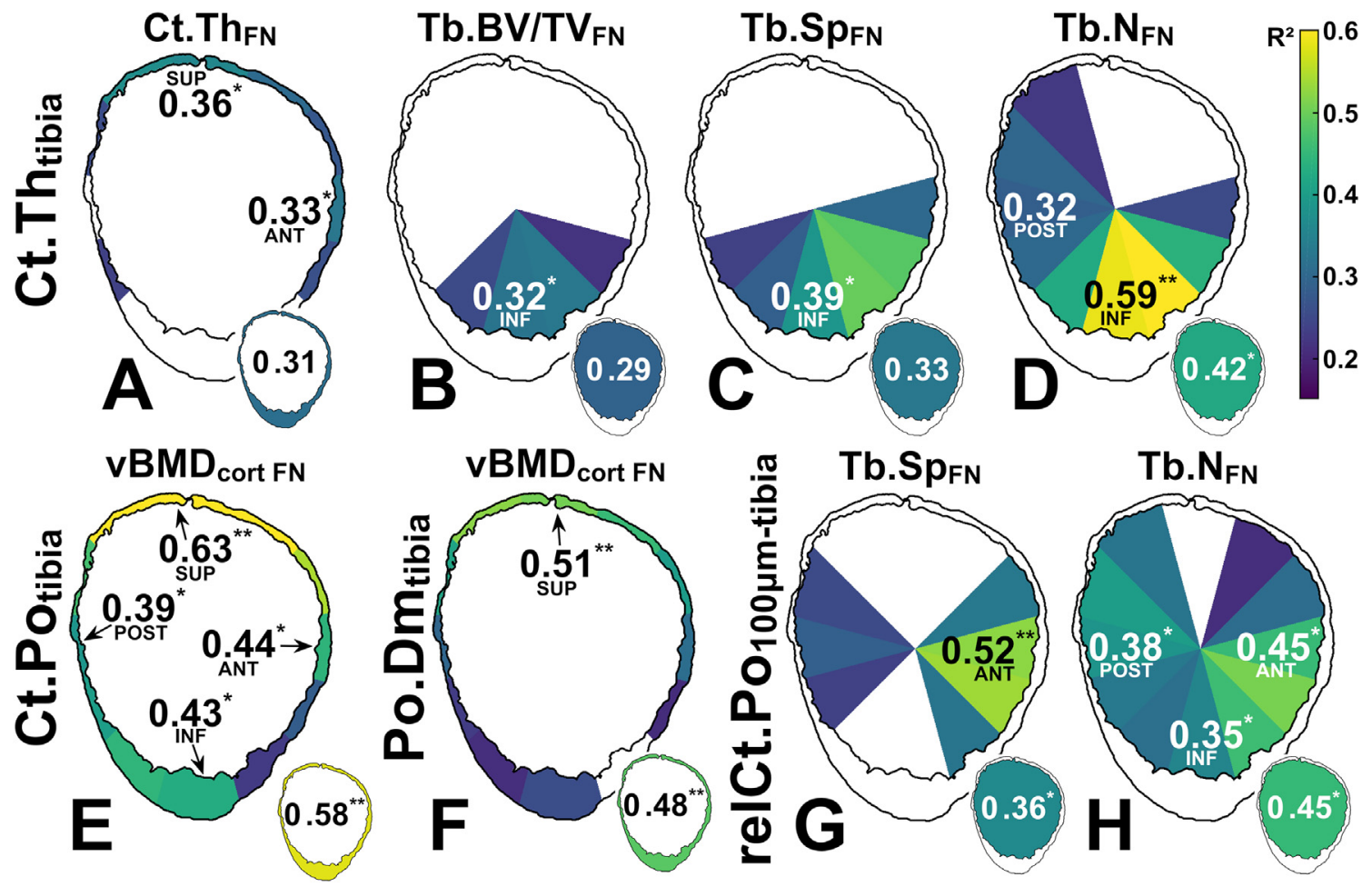

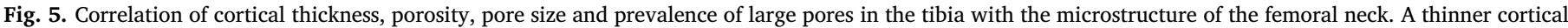

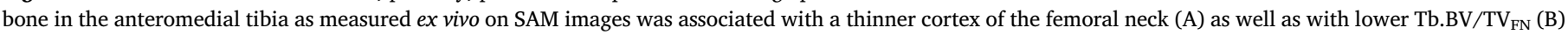

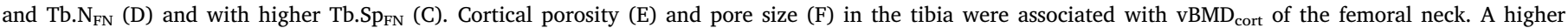

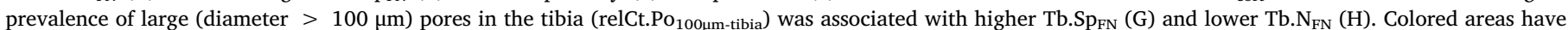

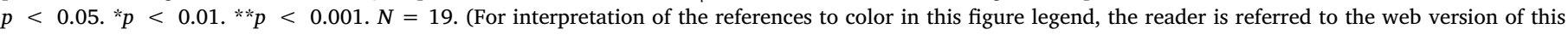
article.)

in Supplemental Fig. 2).

$\mathrm{Ct} \mathrm{Po}_{\text {tibia }}$ and Po.Dm $\mathrm{m}_{\text {tibia }}$ were both strongly associated with $\mathrm{vBMD}_{\text {cort }}$ of the whole FN $\left(\mathrm{R}^{2}=0.58\right.$ and $\mathrm{R}^{2}=0.48$, respectively; $p \leq 0.001$; Table 1 and Fig. 5E, F), even after excluding trabecularized cortical bone regions (panels D and F in Supplemental Fig. 2, respectively). A greater prevalence of large pores in the cortical bone of the tibia (relCt.Po $\mathrm{P}_{100 \mu \mathrm{m} \text {-tibia }}$ ) reflected a lower $\mathrm{FN} \mathrm{vBMD}_{\text {cort }}\left(\mathrm{R}^{2}=0.31\right.$, $p=0.014$; Table 1) as well as larger Tb.Sp $\mathrm{FN}_{\mathrm{F}}\left(\mathrm{R}^{2}=0.36 p<0.01\right.$; Table 1 and Fig. 5G) and lower Tb. $\mathrm{N}_{\mathrm{FN}}\left(\mathrm{R}^{2}=0.45, p<0.01\right.$; Table 1 and Fig. 5H).

\section{Discussion}

In a previous study, we found that variations of proximal femur strength predicted by non-linear homogenized FE models were associated with changes in the cortical bone microstructure of the tibia [25]. Particularly, lower femur strength was strongly associated with a thinner cortex and with the accumulation of large cortical bone pores in the tibia. On the contrary, porosity and average pore size of tibial cortical bone were not associated with femur strength [25]. Associations with femur strength were confirmed for both standing and falling conditions and remained significant when the average strength from left and right femora was considered [25]. One of the aims of this work was to investigate the link between proximal femur strength and distinct features of deterioration of the bone architecture in the femoral neck. During a fall to the side, femoral neck fractures originate in the superior neck [9] as a result of peak compressive strains that can outweigh tensile ones by a factor of two [7]. Such compression leads to the collapse of a bone region which is subject to tension during physiological tasks [6]. The fractured femoral necks of subjects with osteoporosis have been consistently reported to present thinner cortical bone in the superior sub-capital aspect $[10,11,13,42]$. Reduced Ct.Th in this region is a probable cause of structural instability of the femoral neck during a fall to the side, as captured by our simulations of proximal femur failure (Fig. 4A and D).

Considering the trabecular bone of the femoral neck, our study shows significant associations of trabecular density, separation and number with an impairment of the femur strength (Fig. 4B-D). Understanding the relative role of trabecular bone in femoral neck fragility is complicated by the fact that the proportion of trabecular tissue in the femoral neck varies with femur strength [14] and subject age [43] as a result of adaptation to loading [2]. Less dense and sparser trabeculae were observed in fractured femoral necks of OP patients with respect to osteoarthritic control [13]. For elderly subjects, mechanical tests have suggested a marginal role of the spongiosa for femur strength [44], but have considered only standing loads. When sideways fall loads were implemented in numerical simulations (also on an elderly cohort), the contribution to femur strength of the trabecular compartment was similar [6] or even prominent [14] with respect to that of cortical bone. Our results support a combined role of trabecular and cortical bone in determining the stability of the femoral neck in the elderly.

The process underlying cortical bone loss is understood as the uncoupling between resorption and formation phases within remodeling bone multicellular units (BMUs) $[11,45]$. This leads to the progressive enlargement and clustering of non-refilled pores [46-48], to the trabecularization of the endosteal cortical bone region and, subsequently, to the thinning of the cortical wall. Interestingly, the same cellular mechanism (i.e. reversal phase arrest between resorption and formation in the bone remodeling unit) is responsible for trabecular bone loss in post-menopausal osteoporosis [49,50], and has been observed at different skeletal sites such as iliac crest [47,49], proximal femur [45], fibula [45,51] and femoral head [49]. The concept of a common microstructural pattern of bone loss throughout the skeleton, with shared cellular mechanism between cortical and trabecular bone, supports the 
importance of resorption in both tissue types for bone fragility [15].

Our work demonstrates that the signs of bone resorption do not only coexist in trabecular and cortical bone but are also reflected in a similar way in the femoral neck and tibia. A thinner cortical bone in the midshaft of the tibia was associated with a thinner cortex and a less dense, sparser trabecular architecture of the femoral neck. Moreover, a higher proportion of abnormally large cavities in the tibia indicated sparser trabecular structures in the femoral neck. We draw form these findings that local changes of the cortical microstructure in the tibia are associated with a structural deterioration of the femoral neck causing impaired femur strength. If accomplished in a clinical setting, the assessment of the thickness and of large pores in the cortical bone of the tibia might expose conditions of femur fragility in living subjects. To test this hypothesis, databases of HR-pQCT images are already available, that allow studying both retrospectively and prospectively the association between bone microstructure and fracture [52,53]. An ultimate validation of cortical bone microstructural biomarkers against the probability of fracture is necessary, since bone strength examined in a laboratory setting like this one may not translate directly to fracture risk.

HR-pQCT analyses of the cortical bone architecture conducted so far were often limited to the quantification of cortical thickness and porosity. However, HR-pQCT images can be processed to retrieve a diameter and the topology (e.g. orientation and connectivity) of large cortical pores [54,55], while the presence of unresolved cavities can be estimated based on the local gray values $[26,56]$. Spatially registered HR-pQCT and MRI images allow distinguishing fat-filled from vesselfilled pores, which are expected to provide insights on the origin of large cavities in type-II diabetic cortical bone [57]. The direct measurement of the prevalence of large pores requires the quantification of the size of single cavities and remains unfeasible with current technology. However, surrogate measurements of the spatial and size distribution of pores should be incorporated by future investigations on living subjects. Since large pores are encountered mainly in the proximity of the endosteum, the analysis should focus particularly on this deep layer of the tissue.

The portion of the tibia (midshaft) analyzed within this study differs from the one reachable by first-generation HR-pQCT scanners (distal or ultra-distal shaft). Compared to the distal shaft, the mid-diaphysis of the tibia experiences high bending moments during gait [58,59], has a cortical bone that is thicker and is mainly composed of cortical tissue (Fig. 1), making it less affected by axial ROI positioning [60]. MRI, quantitative bone ultrasound as well as second-generation HR-pQCT can be applied to the whole tibia diaphysis. The anteromedial portion was selected for analysis since this site can be easily reached by ultrasound waves that travel with little attenuation through the thin layer of soft tissue covering the facies medialis [19,20].

We confirmed the advantage of this measurement site by repeating the analysis on whole tibia cross-sections: despite being generally weaker, associations with local microstructural features of the femoral neck were confirmed also when taking properties from whole tibial cross sections (Supplemental Table 2). Finally, we asked whether microstructural measurements from the left tibia can reflect changes of femoral neck architecture independent of side: the association between structural changes in the tibia and those in the neck were confirmed independently for left and right femoral necks (Supplemental Table 1).

The current study presents several limitations. First, it does not explain why cortical thinning and accumulation of large pores in the midshaft of the tibia might reflect a thinning of the superior neck, where gait generates tension strains. At the same time, a cortical thinning of the tibia was not associated with a thinner cortex in the inferior neck (the aspect subject to compression during gait) [5]. One reason might be that, in analogy with the superior femoral neck, the anterior aspect of the tibial diaphysis is adapted to resist the tensile stress generated by bending moments in the sagittal plane $[3,59]$. In addition, the distribution of bone tissue around the neck's axis is subject to variability among individuals [2], representing a plausible explanation for the lack of association with the inferior $\mathrm{Ct}_{\mathrm{Th}} \mathrm{Th}_{\mathrm{FN}}$ in our results.

A second limitation of this work consists in the use of structural information from the cortical bone of the tibia obtained ex vivo by SAM with $19.8 \mu \mathrm{m}$ resolution. In the tibia of living humans, such detail of microstructural characterization is unfeasible with current technology. Imaging with second-generation HR-pQCT is not limited to distal ROIs as when the parent, first-generation scanner is used. Newer scanners can assess the tibial midshaft with resolution down to $95.2 \mu \mathrm{m}$ [61]. This makes this modality particularly interesting, since large resorption units can be directly imaged, while assessing Ct.Po based on vBMD beyond the scanner resolution limit [56]. The analysis of the diffusivity [23] and spectral response [21] of ultrasound waves scattered by cortical pores has so far suggested that information on pore size can be retrieved in vivo also with ultrasound.

Even though the shape of the tibia diaphysis can vary along the bone axis [59], the cross-sections analyzed in this study were extracted at varying distance from the upper extremity, thus representing a possible cause of error. Finally, by pooling male and female data together, our work might overlook sex differences in microarchitecture and bone loss at the tibia [62].

\section{Conclusion}

Despite these limitations, our work identifies associations between architectural causes of femoral neck fragility and structural features that can be observed in the cortical bone of the tibia. Our findings support the use of microstructural measurements performed in the cortical bone of the tibia for the prediction of hip fracture risk. Research on living humans should target the assessment of the cortical thickness and of large resorption units in the midshaft of the tibia as potential biomarkers of a structural deterioration of the femoral neck.

Supplementary data to this article can be found online at https:// doi.org/10.1016/j.bone.2020.115446.

\section{CRediT authorship contribution statement}

Gianluca lori:Conceptualization, Methodology, Investigation, Validation, Software, Data curation, Writing - original draft, Writing - review \& editing, Visualization.Johannes Schneider:Investigation, Data curation, Formal analysis.Andreas Reisinger:Methodology, Investigation, Writing - review \& editing, Resources.Frans Heyer:Methodology, Investigation, Data curation.Laura Peralta:Methodology, Investigation, Data curation, Writing - review \& editing.Caroline Wyers:Investigation, Data curation.Claus C. Glüer:Writing - review \& editing, Funding acquisition.J.P. van den Bergh:Writing - review \& editing, Supervision, Resources, Project administration.Dieter Pahr:Validation, Supervision, Resources, Writing - review \& editing.Kay Raum:Conceptualization, Writing review \& editing, Supervision, Project administration, Funding acquisition.

\section{Declaration of competing interest}

KR and GI have the patent application "CortBS: Ultrasonic method for determining pore dimensions in cortical bone" pending.

JS, AR, FH, LP, CW, CCG and DP have nothing to disclose.

JB reports grants and personal fees from Eli Lilly, grants and personal fees from Amgen, grants from Will Pharma, outside the submitted work.

\section{Acknowledgments}

This work was supported by grants from the Deutsche Forschungsgemeinschaft (DFG Ra1380/9-1, Gl 289/8-1), by the Agence 
Nationale de la Recherche (ANR-14-CE35-0030-01), by the Bundesministerium für Bildung und Forschung (BMBF, musculoskeletal research network 01EC1408L) within the subproject "characterization of cortical and subchondral bone", by the German Academic Exchange Service (DAAD, grant no. 91578351) and by the Weijerhorst Foundation (grant no. WH2). We thank Dr. Robert Wendlandt for the sample collection and Dr. Juan Du for the support during data analysis.

\section{References}

[1] P. Fratzl, R. Weinkamer, Nature's hierarchical materials, Prog. Mater. Sci. 52 (2007) 1263-1334, https://doi.org/10.1016/j.pmatsci.2007.06.001.

[2] R.M.D. Zebaze, A. Jones, M. Knackstedt, G. Maalouf, E. Seeman, Construction of the femoral neck during growth determines its strength in old age, J. Bone Miner. Res. 22 (2007) 1055-1061, https://doi.org/10.1359/jbmr.070329.

[3] L. Cristofolini, In vitro evidence of the structural optimization of the human skeletal bones, J. Biomech. 48 (2015) 787-796, https://doi.org/10.1016/j.jbiomech.2014. 12.010 .

[4] M.E. Kersh, S. Martelli, R. Zebaze, E. Seeman, M.G. Pandy, Mechanical loading of the femoral neck in human locomotion, J. Bone Miner. Res.. 0. doi:https://doi.org/ 10.1002/jbmr.3529 (n.d.).

[5] B.V. Rietbergen, R. Huiskes, F. Eckstein, P. Rüegsegger, Trabecular bone tissue strains in the healthy and osteoporotic human femur, J. Bone Miner. Res. 18 (2003) 1781-1788, https://doi.org/10.1359/jbmr.2003.18.10.1781.

[6] E. Verhulp, B. van Rietbergen, R. Huiskes, Load distribution in the healthy and osteoporotic human proximal femur during a fall to the side, Bone 42 (2008) 30-35, https://doi.org/10.1016/j.bone.2007.08.039.

[7] L. Zani, P. Erani, L. Grassi, F. Taddei, L. Cristofolini, Strain distribution in the proximal Human femur during in vitro simulated sideways fall, Journal of Biomechanics 48 (2015) 2130-2143, https://doi.org/10.1016/j.jbiomech.2015.02. 022.

[8] J.H. Keyak, H.B. Skinner, J.A. Fleming, Effect of force direction on femoral fracture load for two types of loading conditions, J. Orthop. Res. 19 (2001) 539-544, https://doi.org/10.1016/S0736-0266(00)00046-2.

[9] P.M. de Bakker, S.L. Manske, V. Ebacher, T.R. Oxland, P.A. Cripton, P. Guy, During sideways falls proximal femur fractures initiate in the superolateral cortex: evidence from high-speed video of simulated fractures, J. Biomech. 42 (2009) 1917-1925, https://doi.org/10.1016/j.jbiomech.2009.05.001.

[10] K.E.S. Poole, G.M. Treece, P.M. Mayhew, J. Vaculík, P. Dungl, M. Horák, J.J. Štěpán, A.H. Gee, Cortical thickness mapping to identify focal osteoporosis in patients with hip fracture, PLoS One 7 (2012) e38466, , https://doi.org/10.1371/ journal.pone.0038466.

[11] J. Power, N. Loveridge, H. Kröger, M. Parker, J. Reeve, Femoral neck cortical bone in female and male hip fracture cases: differential contrasts in cortical width and sub-periosteal porosity in 112 cases and controls, Bone 114 (2018) 81-89, https:// doi.org/10.1016/j.bone.2018.05.027.

[12] F. Johannesdottir, K.E.S. Poole, J. Reeve, K. Siggeirsdottir, T. Aspelund, B. Mogensen, B.Y. Jonsson, S. Sigurdsson, T.B. Harris, V.G. Gudnason, G. Sigurdsson, Distribution of cortical bone in the femoral neck and hip fracture: a prospective case-control analysis of 143 incident hip fractures; the AGESREYKJAVIK study, Bone 48 (2011) 1268-1276, https://doi.org/10.1016/j.bone. 2011.03.776.

[13] H. Blain, P. Chavassieux, N. Portero-Muzy, F. Bonnel, F. Canovas, M. Chammas, P. Maury, P.D. Delmas, Cortical and trabecular bone distribution in the femoral neck in osteoporosis and osteoarthritis, Bone 43 (2008) 862-868, https://doi.org/ 10.1016/j.bone.2008.07.236.

[14] S. Nawathe, H. Akhlaghpour, M.L. Bouxsein, T.M. Keaveny, Microstructural failure mechanisms in the human proximal femur for sideways fall loading, J. Bone Miner. Res. 29 (2014) 507-515, https://doi.org/10.1002/jbmr.2033.

[15] E. Seeman, Pathogenesis of bone fragility in women and men, Lancet 359 (2002) 1841-1850, https://doi.org/10.1016/S0140-6736(02)08706-8.

[16] K.K. Nishiyama, H.M. Macdonald, H.R. Buie, D.A. Hanley, S.K. Boyd, Postmenopausal women with osteopenia have higher cortical porosity and thinner cortices at the distal radius and tibia than women with normal aBMD: an in vivo HR-pQCT study, J. Bone Miner. Res. 25 (2010) 882-890, https://doi.org/10.1359/ jbmr.091020.

[17] P. Christen, S. Boutroy, R. Ellouz, R. Chapurlat, B. van Rietbergen, Least-detectable and age-related local in vivo bone remodelling assessed by time-lapse HR-pQCT, PLoS One 13 (2018) e0191369, , https://doi.org/10.1371/journal.pone.0191369.

[18] C. Ohlsson, D. Sundh, A. Wallerek, M. Nilsson, M. Karlsson, H. Johansson, D. Mellström, M. Lorentzon, Cortical bone area predicts incident fractures independently of areal bone mineral density in older men, J. Clin. Endocrinol. Metab. 102 (2017) 516-524, https://doi.org/10.1210/jc.2016-3177.

[19] J. Schneider, D. Ramiandrisoa, G. Armbrecht, Z. Ritter, D. Felsenberg, K. Raum, J.G. Minonzio, In vivo measurements of cortical thickness and porosity at the proximal third of the tibia using guided waves: comparison with site-matched peripheral quantitative computed tomography and distal high-resolution peripheral quantitative computed tomography, Ultrasound Med. Biol. 45 (2019) 1234-1242, https:// doi.org/10.1016/j.ultrasmedbio.2019.01.008.

[20] G. Renaud, P. Kruizinga, D. Cassereau, P. Laugier, In vivo ultrasound imaging of the bone cortex, Phys. Med. Biol. 63 (2018) 125010, , https://doi.org/10.1088/1361$6560 /$ aac784.

[21] H. Nguyen Minh, J. Du, K. Raum, Estimation of thickness and speed of sound in cortical bone using multifocus pulse-echo ultrasound, IEEE Trans. Ultrason. Ferroelectr. Freq. Control 67 (2020) 568-579, https://doi.org/10.1109/TUFFC. 2019.2948896.

[22] J.-G. Minonzio, N. Bochud, Q. Vallet, D. Ramiandrisoa, A. Etcheto, K. Briot, S. Kolta, C. Roux, P. Laugier, Ultrasound-based estimates of cortical bone thickness and porosity are associated with non-traumatic fractures in postmenopausal women: a pilot study, J. Bone Miner. Res. 0 (2019), https://doi.org/10.1002/jbmr.3733.

[23] Y. Karbalaeisadegh, O. Yousefian, G. Iori, K. Raum, M. Muller, Acoustic diffusion constant of cortical bone: numerical simulation study of the effect of pore size and pore density on multiple scattering, J. Acoust. Soc. Am. 146 (2019) 1015-1023, https://doi.org/10.1121/1.5121010.

[24] J. Du, G. Iori, K. Raum, In-silico validation of microstructure estimation from cortical bone backscatter, http://sites.ieee.org/ius-2018/, (2018).

[25] G. Iori, J. Schneider, A. Reisinger, F. Heyer, L. Peralta, C. Wyers, M. Gräsel, R. Barkmann, C.C. Glüer, J.P. van den Bergh, D. Pahr, K. Raum, Large cortical bone pores in the tibia are associated with proximal femur strength, PLoS One 14 (2019) e0215405, , https://doi.org/10.1371/journal.pone.0215405.

[26] G. Iori, F. Heyer, V. Kilappa, C. Wyers, P. Varga, J. Schneider, M. Gräsel, R. Wendlandt, R. Barkmann, J.P. van den Bergh, K. Raum, BMD-based assessment of local porosity in human femoral cortical bone, Bone 114 (2018) 50-61, https:// doi.org/10.1016/j.bone.2018.05.028.

[27] E. Dall'Ara, B. Luisier, R. Schmidt, F. Kainberger, P. Zysset, D. Pahr, A nonlinear QCT-based finite element model validation study for the human femur tested in two configurations in vitro, Bone 52 (2013) 27-38, https://doi.org/10.1016/j.bone. 2012.09.006.

[28] G. Iori, L. Peralta, A. Reisinger, F. Heyer, C. Wyers, J. van den Bergh, D. Pahr, K. Raum, Femur strength predictions by nonlinear homogenized voxel finite element models reflect the microarchitecture of the femoral neck, Med. Eng. Phys. (2020), https://doi.org/10.1016/j.medengphy.2020.03.005.

[29] D. Garcia, P.K. Zysset, M. Charlebois, A. Curnier, A three-dimensional elastic plastic damage constitutive law for bone tissue, Biomech. Model. Mechanobiol. 8 (2008) 149-165, https://doi.org/10.1007/s10237-008-0125-2.

[30] L. Rincón-Kohli, P.K. Zysset, Multi-axial mechanical properties of human trabecular bone, Biomech. Model. Mechanobiol. 8 (2008) 195-208, https://doi.org/10.1007/ s10237-008-0128-z.

[31] S. Lakshmanan, A. Bodi, K. Raum, Assessment of anisotropic tissue elasticity of cortical bone from high-resolution, angular acoustic measurements, IEEE Trans. Ultrason. Ferroelectr. Freq. Control 54 (2007) 1560-1570, https://doi.org/10. 1109/TUFFC. 2007.426.

[32] K. Raum, J. Reißhauer, J. Brandt, Frequency and resolution dependence of the anisotropic impedance estimation in cortical bone using time-resolved scanning acoustic microscopy, J. Biomed. Mater. Res. 71A (2004) 430-438, https://doi.org/ 10.1002/jbm.a.30156.

[33] R. Hube, H. Mayr, W. Hein, K. Raum, Prediction of biomechanical stability after callus distraction by high resolution scanning acoustic microscopy, Ultrasound Med. Biol. 32 (2006) 1913-1921, https://doi.org/10.1016/j.ultrasmedbio.2006.06. 010 .

[34] M.J. Hartel, A. Petersik, A. Schmidt, D. Kendoff, J. Nüchtern, J.M. Rueger, W. Lehmann, L.G. Grossterlinden, Determination of femoral neck angle and torsion angle utilizing a novel three-dimensional modeling and analytical technology based on CT datasets, PLoS One 11 (2016) e0149480, , https://doi.org/10.1371/journal. pone.0149480.

[35] R. Dana Carpenter, S. Beaupré Gary, Thomas F. Lang, Eric S. Orwoll, Dennis R. Carter, New QCT analysis approach shows the importance of fall orientation on femoral neck strength, J. Bone Miner. Res. 20 (2009) 1533-1542, https://doi.org/ 10.1359/JBMR.050510.

[36] T. Lang, J. Keyak, M. Heitz, P. Augat, Y. Lu, A. Mathur, H. Genant, Volumetric quantitative computed tomography of the proximal femur: precision and relation to bone strength, Bone 21 (1997) 101-108.

[37] A.J. Burghardt, H.R. Buie, A. Laib, S. Majumdar, S.K. Boyd, Reproducibility of direct quantitative measures of cortical bone microarchitecture of the distal radius and tibia by HR-pQCT, Bone 47 (2010) 519-528, https://doi.org/10.1016/j.bone.2010. 05.034.

[38] T. Ridler, S. Calvard, et al., Picture thresholding using an iterative selection method, IEEE Trans. Syst. Man Cybern. 8 (1978) 630-632.

[39] T. Hildebrand, P. Rüegsegger, A new method for the model-independent assessment of thickness in three-dimensional images, J. Microsc. 185 (1997) 67-75, https:// doi.org/10.1046/j.1365-2818.1997.1340694.x.

[40] P.D. Wellner, Adaptive Thresholding for the DigitalDesk, Xerox, EPC1993-110, (1993), pp. 1-19.

[41] M.K.H. Malo, D. Rohrbach, H. Isaksson, J. Töyräs, J.S. Jurvelin, I.S. Tamminen, H. Kröger, K. Raum, Longitudinal elastic properties and porosity of cortical bone tissue vary with age in human proximal femur, Bone 53 (2013) 451-458, https:// doi.org/10.1016/j.bone.2013.01.015.

[42] K.L. Bell, N. Loveridge, J. Power, N. Garrahan, M. Stanton, M. Lunt, B.F. Meggitt, J. Reeve, Structure of the femoral neck in hip fracture: cortical bone loss in the inferoanterior to superoposterior axis, J. Bone Miner. Res. 14 (1999) 111-119, https://doi.org/10.1359/jbmr.1999.14.1.111.

[43] H. Chen, X. Zhou, S. Shoumura, S. Emura, Y. Bunai, Age- and gender-dependent changes in three-dimensional microstructure of cortical and trabecular bone at the human femoral neck, Osteoporos. Int. 21 (2010) 627-636, https://doi.org/10. 1007/s00198-009-0993-z.

[44] G. Holzer, G. von Skrbensky, L.A. Holzer, W. Pichl, Hip fractures and the contribution of cortical versus trabecular bone to femoral neck strength, J. Bone Miner. Res. 24 (2009) 468-474, https://doi.org/10.1359/jbmr.081108.

[45] N.E. Lassen, T.L. Andersen, G.G. Pløen, K. Søe, E.M. Hauge, S. Harving, 
G.E.T. Eschen, J.-M. Delaisse, Coupling of bone resorption and formation in real time: new knowledge gained from human Haversian BMUs, J. Bone Miner. Res. 32 (2017) 1395-1405, https://doi.org/10.1002/jbmr.3091.

[46] K.L. Bell, N. Loveridge, J. Power, N. Garrahan, B.F. Meggitt, J. Reeve, Regional differences in cortical porosity in the fractured femoral neck, Bone 24 (1999) 57-64, https://doi.org/10.1016/S8756-3282(98)00143-4.

[47] C.M. Andreasen, J.-M. Delaisse, B.C. van der Eerden, J.P. van Leeuwen, M. Ding, T.L. Andersen, Understanding age-induced cortical porosity in women: the accumulation and coalescence of eroded cavities upon existing intracortical canals is the main contributor, J. Bone Miner. Res. 33 (2017) 606-620, https://doi.org/10. 1002/jbmr.3354.

[48] G.R. Jordan, N. Loveridge, K.L. Bell, J. Power, N. Rushton, J. Reeve, Spatial clustering of remodeling osteons in the femoral neck cortex: a cause of weakness in hip fracture? Bone 26 (2000) 305-313, https://doi.org/10.1016/S8756-3282(99) 00272-0.

[49] T.L. Andersen, E.M. Hauge, L. Rolighed, J. Bollerslev, P. Kjærsgaard-Andersen, J.M. Delaisse, Correlation between absence of bone remodeling compartment canopies, reversal phase arrest, and deficient bone formation in post-menopausal osteoporosis, Am. J. Pathol. 184 (2014) 1142-1151, https://doi.org/10.1016/j. ajpath.2013.12.005.

[50] C.M. Andreasen, M. Ding, S. Overgaard, P. Bollen, T.L. Andersen, A reversal phase arrest uncoupling the bone formation and resorption contributes to the bone loss in glucocorticoid treated ovariectomised aged sheep, Bone 75 (2015) 32-39, https:// doi.org/10.1016/j.bone.2015.02.014.

[51] L.P. Bakalova, C.M. Andreasen, J.S. Thomsen, A. Brüel, E.-M. Hauge, B.J. Kiil, J.M. Delaisse, T.L. Andersen, M.E. Kersh, Intracortical bone mechanics are related to pore morphology and remodeling in human bone, J. Bone Miner. Res. 33 (2018) 2177-2185, https://doi.org/10.1002/jbmr.3561.

[52] H.A. Fink, L. Langsetmo, T.N. Vo, E.S. Orwoll, J.T. Schousboe, K.E. Ensrud, Association of High-resolution Peripheral Quantitative Computed Tomography (HR-pQCT) bone microarchitectural parameters with previous clinical fracture in older men: the Osteoporotic Fractures in Men (MrOS) study, Bone 113 (2018) 49-56, https://doi.org/10.1016/j.bone.2018.05.005.

[53] V.V. Shanbhogue, K. Brixen, S. Hansen, Age- and sex-related changes in bone microarchitecture and estimated strength: a three-year prospective study using HRpQCT, J. Bone Miner. Res. 31 (2016) 1541-1549, https://doi.org/10.1002/ jbmr.2817.

[54] J.M. Patsch, A.J. Burghardt, S.P. Yap, T. Baum, A.V. Schwartz, G.B. Joseph, T.M. Link, Increased cortical porosity in type 2 diabetic postmenopausal women with fragility fractures, J. Bone Miner. Res. 28 (2013) 313-324, https://doi.org/10 1002/jbmr.1763.

[55] W. Tjong, J. Nirody, A.J. Burghardt, J. Carballido-Gamio, G.J. Kazakia, Structural analysis of cortical porosity applied to HR-pQCT data, Med. Phys. 41 (2014), https://doi.org/10.1118/1.4851575.

[56] R. Zebaze, A. Ghasem-Zadeh, A. Mbala, E. Seeman, A new method of segmentation of compact-appearing, transitional and trabecular compartments and quantification of cortical porosity from high resolution peripheral quantitative computed tomographic images, Bone 54 (2013) 8-20, https://doi.org/10.1016/j.bone.2013.01. 007.

[57] P. Wu, M. Gibbons, S. Foreman, J. Carballido-Gamio, R. Krug, J. Liu, T.M. Link, G.J. Kazakia, Multi-Modality In Vivo Detection of Cortical Bone Vasculature: Comparison of Diabetes Patients to Healthy Controls, https://qmski.org/, (2019).

[58] T. Wehner, L. Claes, U. Simon, Internal loads in the human tibia during gait, Clin. Biomech. 24 (2009) 299-302, https://doi.org/10.1016/j.clinbiomech.2008.12.007.

[59] L. Cristofolini, E. Angeli, J.M. Juszczyk, M.M. Juszczyk, Shape and function of the diaphysis of the human tibia, J. Biomech. 46 (2013) 1882-1892, https://doi.org/ 10.1016/j.jbiomech.2013.04.026.

[60] S.K. Boyd, Site-specific variation of bone micro-architecture in the distal radius and tibia, J. Clin. Densitom. 11 (2008) 424-430, https://doi.org/10.1016/j.jocd.2007. 12.013.

[61] S.L. Manske, Y. Zhu, C. Sandino, S.K. Boyd, Human trabecular bone microarchitecture can be assessed independently of density with second generation HRpQCT, Bone 79 (2015) 213-221, https://doi.org/10.1016/j.bone.2015.06.006.

[62] N. Dalzell, S. Kaptoge, N. Morris, A. Berthier, B. Koller, L. Braak, B. van Rietbergen, J. Reeve, Bone micro-architecture and determinants of strength in the radius and tibia: age-related changes in a population-based study of normal adults measured with high-resolution pQCT, Osteoporos. Int. 20 (2009) 1683-1694, https://doi.org/ 10.1007/s00198-008-0833-6. 